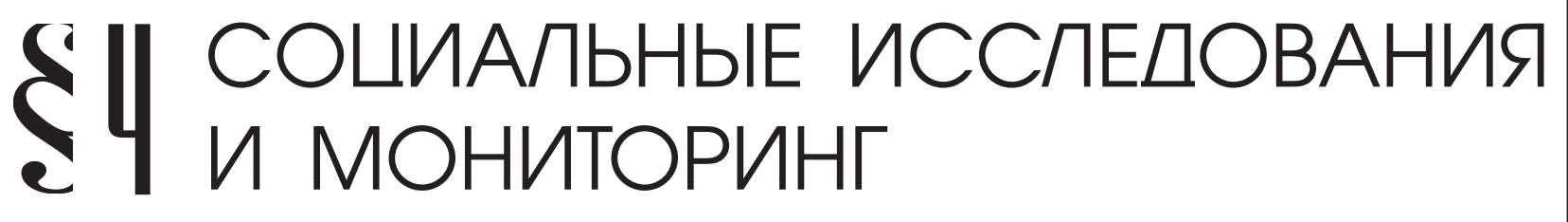

Береговая Е.В.

\section{МИРОВАЯ ЮСТИЦИЯ \\ В РОССИЙСКОЙ ПОЛИТИЧЕСКОЙ СИСТЕМЕ (ПО МАТЕРИАЛАМ СОЦИОЛОГИЧЕСКОГО ИССЛЕДОВАНИЯ)}

\begin{abstract}
Аннотация: Мировой юстицией разрешается подавляющее количество судебных дел и её влияние на формирование политического сознания граждан наиболее масштабно. Однако политические аспекты института мировой юстиции слабо изучены. С челью выяснения представлений о роли и перспективах развития мировой юстиции 8 российской политической системе проведен сочиологический опрос среди мировых судей и гражданских служащих их аппаратов в Республике Коми и в Пермском крае. Результаты соииологического исследования показали недооценку политической роли мировой юстиции самими представителями этого института, видение перспективы её развития в качестве низшего звена судебной системы. Остро обсуждаемая в научных кругах проблема двойственности статуса мирового судьи не нашла подтверждения своей актуальности среди носителей судебной власти, приспособившихся работать в реально существуюших политико-правовых условиях. В числе основных факторов, влияющих, по мнению респондентов, на независимость мировых судей, указано назначение мирового судьи законодательными органами субъекта Российской Федераиии. Не случайно в вопросе о порядке назначения на должность мирового судьи преобладает вариант его назначения высшим судейским органом субъекта России. Результаты опроса могут использоваться в политологических и юридических исследованиях.
\end{abstract}

Review: The justices of peace deal with most of the judicial cases and their influence upon the political cognition of the people is large-scale. However, political aspects of this institution are not sufficiently studied. In order to find out the opinions on the role and perspectives of the justices of peace within the political system of Russia, the author held a poll among the justices of peace and the civil state servants from their staff in the Komi Republic and Perm region. The results of the sociological study showed the underestimation of the political role of the justices of peace by the very representatives of this institution, the vision of its perspective of development as a lowest branch of the judicial system. The topical scientific problem of dual status of a justice of peace was not supported as topical among the judges, working in current political and legal conditions. Among the factors influencing the independence of justices of peace the assignment of judges by the legislative bodies of the constituent subjects of the Russian Federation was pointed out. It is not accidental, that the assignment of justices of peace by the highest judicial body of the constituent subject of the Russian Federation is supported. The results of the poll may be used for political and legal studies.

Ключевые слова: Судебная власть, мировая юстииия, политические аспекты, политическая роль, перспективы развития, соичологический опрос, Республика Коми, Пермский край, мировой судья, политикоправовой статус

Keywords: judicial power, justices of peace, political aspects, political role, perspectives of development, sociological poll, the Komi Republic, Perm region, justice of peace, political and legal status.

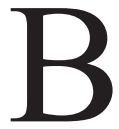

ысокий уровень конфликтной напряженности отмечается исследователями как характерная черта российского общества ${ }^{1}$. Традиционным

\footnotetext{
${ }^{1}$ Понасюк A. М. Медиация как альтернатива и дополнение судопроизводству // Мировой судья. - 2012. - № 9. - С. 8.
}

становится разрешение споров с помощью правосудия. Это сказывается на высоком уровне рабочей нагрузки судей, отсутствии возможности для полного и всестороннего рассмотрения дела по существу и, как следствие, частое нарушение установленных сроков судопроизводства, снижение эффективности судеб- 
ной защиты прав. Принимая во внимание указанные обстоятельства, актуальными становятся вопросы организации правосудия в России, особенно на низшем уровне - на уровне мировых судей, которыми рассматривается подавляющее большинство судебных дел в 2010 году $79 \%$ от общего количества дел, рассмотренных судами общей юрисдикции, в 2011 - 77 \%, в $2012-75 \%$. Это незначительные, «бытовые» дела, но их количество свидетельствует о том, что нередко первый опыт граждан личного «знакомства» с работой судебной системы происходит у мирового судьи. На основе такого опыта складываются представления граждан о судебной власти в целом, о власти вообще, а также о таких ценностных категориях, как право, справедливость, истина.

Интересны в этом плане представления самих мировых судей и гражданских служащих их аппаратов о роли и перспективах развития мировой юстиции в российской политической системе. С целью выявления данных представлений в марте 2013 года нами проводился опрос, в котором приняли участие мировые судьи и гражданские служащие их аппаратов в Республике Коми и в Пермском крае.

Всего в опросе приняли участие 120 респондентов (34 мировых судьи и 86 гражданских служащих):

- в Республике Коми (далее - РК): 19 мировых судей из 60 по штату (32\% от общего количества) и 67 гражданских служащих, состоящих в аппарате мирового судьи, из 180 по штату (37\% от общего количества);

- в Пермском крае (далее - ПК): 15 мировых судей из 146 по штату (10\% от общего количества) и 19 гражданских служащих, состоящих в аппарате мирового судьи, из 292 по штату (7 \% от общего количества).

Активность участия в опросе мировых судей и гражданских служащих не высокая, что свидетельствует о незаинтересованности самих представителей изучаемого института в нем и, можно предположить, низком уровне идентификации опрашиваемых с принадлежностью к институту мировой юстиции в перспективе.

По результатам опроса анализировались представления мировых судей и гражданских служащих о миссии и призвании мировой юстиции. Характерно, что

\footnotetext{
${ }^{2}$ Судебный департамент при Верховном Суде Российской Федерации : [офиц. сайт]. URL: http://www.cdep.ru/index. php?id=79\&item=1627 (дата обращения: 23.05.2013).
}

по вопросу «Миссия мировой юстиции заключается в том, чтобы...» респонденты выбрали ответ «обеспечивать порядок и законность в обществе» (57\%, при этом $59 \%$ в РК и 50 \% в ПК). Значительное число респондентов (40\%, при этом $40 \%$ в РК и $41 \%$ в ПК) указали, что миссия мировой юстиции состоит в том, чтобы разгрузить судебную систему, т.е. акцентировали значение миссии института на технологическом аспекте. При этом подавляющее большинство респондентов на вопрос о призвании мировой юстиции выбрало ответ «в упрощенном порядке и в рамках закона разрешать споры и дела» (62 \%, при этом 64 \% в РК и 56 \% в ПК), что также отражает технологический подход и, по сути, нивелирует истинное призвание мировой юстиции как судебной власти - устанавливать справедливость, искать истину (такой ответ выбрало лишь $28 \%$ респондентов, при этом $23 \%$ в РК, значительно больше в ПК - 38 \%).

Еще меньшее количество респондентов остановило свой выбор на призвании мировой юстиции способствовать установлению конструктивных отношений между спорящими сторонами (11 \% при этом $13 \%$ в РК, а в ПК такого мнения придерживаются только мировые судьи - 6 \% от числа респондентов в ПК). По нашему мнению, данный вариант ответа отражает специфику мировой юстиции, одной из важных функций которой является примирение спорящих сторон. Однако сами представители мировой юстиции (прежде всего мировые судьи) такой специфики своей профессиональной деятельности не чувствуют.

Миссию мировой юстиции в том, чтобы способствовать снятию в обществе социальной напряженности, видят 3 \% опрошенных - все они гражданские служащие (1 \% в РК и 9 \% в ПК). Вариант ответа о миссии мировой юстиции, имеющий политическую окраску («способствовать формированию лояльного отношения к власти»), остался без внимания. Низкие показатели данных вариантов ответов о миссии мировой юстиции объяснимы, с одной стороны, тем, что респонденты являются практикующими юристами, а с другой, - разумеющимся является преобладание в миссии мировой юстиции правовой (судебной) сущности данного института над социально-политической.

На вопрос о приближенности мировой юстиции к населению преобладает ответ о том, что мировая юстиция - это наиболее приближенное к населению звено судебной системы (58 \%, при этом 56 \% в РК и $65 \%$ 


\section{Политика и общество 8 (104) • 2013}

в ПК). Процент опрошенных, придерживающихся данного мнения, среди мировых судей выше (68 \% по обоим регионам в совокупности), чем среди гражданских служащих (55 \%). Возможно, судьи учитывали не просто территориальную, но и процессуальную приближенность мировой юстиции к населению (т.е. упрощенность процессуальных процедур рассмотрения дел).

Остальные респонденты считают, что мировой суд приближен к населению не более, чем федеральные суды (31\%, при этом 37 \% в РК и $15 \%$ в ПК), либо, что мировой суд не столь приближен к населению, как того требует миссия мировой юстиции (11\%, при этом 7 \% в РК и $21 \%$ в ПК). Очевидно, что на ответы оказала влияние нерешенность вопроса о максимальной территориальной приближенности в части расположения помещений судебных участков на территории границ этих самых судебных участков - данная проблема касается прежде всего городов и районов, где помещения нескольких судебных участков сконцентрированы в одном месте. Характерно, что в РК из данных двух вариантов преобладает первый («мировой суд приближен к населению не более, чем федеральные суды»), что вероятно обусловлено расположением помещений судебных участков, как правило, в местностях расположения федеральных районных (городских) судов.

Большинство респондентов соглашаются с тем, что мировая юстиция оказывает существенное влияние на представления граждан о справедливости, законности, власти, формируя политическое сознание общества (56 \%, при этом 55 \% в РК и $59 \%$ в ПК). В то же время $19 \%$ опрошенных (при этом $17 \%$ в РК и $24 \%$ в ПК) считает, что влияние мировой юстиции на представления граждан о справедливости, законности, власти не значительно, а $25 \%$ респондентов (28 \% в РК и 18 \% в ПК) указали, что мировая юстиция не имеет отношения к политическому сознанию общества. Последний ответ преобладает в РК, причем процент опрошенных мировых судей РК, считающих таким образом, выше (32\%), чем гражданских служащих их аппаратов (27\%).

Возможно, что несоотнесение исследуемого института с политическим сознанием обусловлено господством представлений о суде исключительно как о правовом институте. Такое представление усиливается в отношение мировой юстиции как нижнем звене судебной системы. Хотя объективно суд (любое его звено) влияет на политическое сознание общества, что не раз становилось предметом научных исследований, подтверждающих данный вывод³.

В вопросе о взаимосвязи исследуемого института с политическим режимом большинство респондентов считает, что мировая юстиция необходима в современной системе власти независимо от политического режима (74\%, при этом $72 \%$ в РК и $79 \%$ в ПК). По данному вопросу высок разрыв в проценте ответов между мировыми судьями РК (58 \%) и гражданскими служащими их аппаратов (76 \%). Непосредственные носители судебной власти в РК чаще соотносят себя с воплощением демократических идей, выбирая ответ о мировой юстиции как неотъемлемом атрибуте демократического режима (32\% против $18 \%$ среди опрошенных гражданских служащих в РК), но в целом такого мнения придерживаются всего лишь $20 \%$ опрошенных (21\% в РК и $18 \%$ в ПК).

$6 \%$ респондентов (7\% в РК и $3 \%$ в ПК) полагает, что мировая юстиция может эффективно функционировать в государствах как с демократическим режимом, так и с авторитарным политическим режимом. Можно заключить, что мировая юстиция её представителями воспринимается как необходимый и особый элемент современной судебной системы, не связанный с характером политического режима.

Не случайно подавляющее большинство респондентов считают мировой суд основным, нижним звеном судебной системы общей юрисдикции (78 \%, при этом $81 \%$ в РК и 71 \% в ПК). Напротив, $18 \%$ опрошенных (16 \% в РК и $24 \%$ в ПК) полагают, что мировая юстиция должна быть самостоятельной ветвью судебной власти субъекта Российской Федерации со своей системой пересмотров решений мировых судей. $3 \%$ опрошенных (2 \% в РК и 6 \% в ПК) не выбрали ни тот, ни другой вариант. Один из респондентов, не выбравший ни один из предложенных вариантов, уточнил свою позицию в связи с тем, что мировые судьи имеют равный с районными (городскими) судами статус. Соглашаясь с данным утверждением, приходим к выводу о том, что мировая юстиция вместе с федеральными судами местного уровня (районными и го-

\footnotetext{
3 Иванова T. В. Судебная власть в контексте проблемы понимания феномена власти // Вестн. Полоц. гос. ун-та. Сер. D. Эконом. и юрид. науки. - 2008. - № 10. - C. 133-138 ; Пасечник Н. В. Политические аспекты судебной власти в современной России : Дис. ... канд. полит. наук. - Саратов, 2005. - 189 с. ; Серый В. В. Имидж судебной власти в России как отражение социально-политических процессов : Автореф. дис. ... канд. полит. наук. - М., 2011. - 25 с.
} 
родскими) образуют нижнее звено судебной системы общей юрисдикции, являясь первой инстанцией, но отличаясь юрисдикцией: мировые судьи рассматривают категории малозначительных дел, районные и городские суды - более серьезные дела.

Большинство респондентов (61\%, при этом $62 \%$ в РК и $59 \%$ в ПК) не согласны с мнением, что приравнивание к статусу федеральных судей правового статуса мировых судей, являющихся судьями субъекта России, создает двойственное, неопределенное положение мировой юстиции в судебной системе. $39 \%$ принявших участие в опросе (38 \% в РК и $41 \%$ в ПК), напротив, видят в такой ситуации неопределенность статуса мирового судьи.

Отметим, что в научных кругах активно обсуждается проблема двойственности статуса мирового судьи: одни исследователи сводят решение проблемы к обеспечению деятельности мировых судей и необходимости передачи данной функции от субъектов России на федеральный уровень ${ }^{4}$, другие против усиления центральной власти и видят перспективы развития мировой юстиции в дальнейшем её оформлении как судебной власти субъекта Российской Федерации 5 . Однако результаты нашего опроса не показывают актуальность данной проблемы среди представителей института мировой юстиции, приспособившихся работать в реально существующих политико-правовых условиях.

В вопросе о порядке назначения на должность мирового судьи нет единодушия. В РК наибольшее количество ответов получил вариант «назначаться высшим судейским органом субъекта России» (48 \%, при этом 58 \% мировых судей, 45 \% гражданских служащих). В ПК такого же мнения придерживается только $35 \%$ респондентов, но среди них мировых судей только $27 \%$, а гражданских служащих - $42 \%$. Итоговое же распределение по данному ответу среди мировых судей и работников их аппаратов равное $44 \%$, соответственно такова же доля среди опрошенных обоих регионов в целом.

\footnotetext{
${ }^{4}$ Гарифуллина А. Р. Некоторые аспекты организационного обеспечения деятельности мировых судей // Рос. судья. - 2012. - № 6. - С. 10 ; Дорошков В. В. 10-летний юбилей института мировых судей в России и перспективы его дальнейшего развития // Мировой судья. - 2009. - № 1. - С. 5.

${ }_{5}^{5}$ Терехин В.A. К вопросу о возможности передачи мировой юстиции на федеральный уровень // Рос. юстиция. - 2009. -
} № 2. - C. 27.
Чуть меньше (36 \%) опрошенных придерживаются существующего порядка назначения мировых судей назначение органом законодательной власти субъекта России. При этом в ПК данное мнение выразило большинство респондентов (44 \%), а в РК - треть их (33\%).

В равной степени распределилось количество респондентов (по $10 \%$ ) в вариантах ответов «избираться населением» и «назначаться высшим должностным лицом субъекта России». При этом сторонников демократического способа - избрания мирового судьи населением - в РК вдвое больше, чем в ПК (12 против $6 \%$ ), к тому же в РК больше гражданские служащие, нежели служители фемиды, придерживаются данного мнения (13 против $5 \%$ ). Напротив, в ПК больше чем в РК (15 против $8 \%)$ - за назначение мирового судьи высшим должностным лицом субъекта России, при этом процент мировых судей ПК, высказавших такое мнение, почти вдвое преобладает над аналогичным показателем среди гражданских служащих ПК (20 против 11).

Субъекты Российской Федерации при формировании института мировой юстиции имеют право выбора порядка наделения мирового судьи полномочиями и решения вопроса о том, назначать им или избирать мировых судей. Однако все российские регионы пошли по пути назначения мировых судей на должность. Сложившаяся практика подвергается резкой критике в научных кругах ${ }^{6}$, однако сами представители фемиды, как показал опрос, разделяют её востребованность.

Подавляющее большинство участников опроса ( $89 \%$, при этом $90 \%$ в РК и 88 \% в ПК) считают, что на мнение мирового судьи при отправлении им правосудия политическая обстановка не влияет, мировой судья беспристрастен. Тем не менее, 8 \% опрошенных ( 8 \% в РК и $9 \%$ в ПК) полагают, что политическая обстановка не может не влиять на мнение мирового судьи, т.к. он субъект политических отношений, a $3 \%$ (2 \% в РК и $3 \%$ в ПК) - уверены, что политическая обстановка (политический курс Президента РФ, Правительства РФ, руководящих органов субъекта России) влияет на мнение мирового судьи. Данный

\footnotetext{
${ }^{6}$ Ржевский В. А., Чепурнова Н. М. Судебная власть в Российской Федерации: конституционные основы организации и деятельности. - М.: Юрист, 1998. - С. 171-172; Муратшина Г. П. Организация судебной власти в Республике Башкортостан (на примере мировых судей) // Мировой судья. - 2012. - № 9. C. 26 ; Салчак A. А. Мировая юстиция в Республике Тыва (проблемы законодательного регулирования деятельности мировых судей) // Мировой судья. - 2010. - № 12. - С. 4.
} 


\section{Политика и общество 8 (104) • 2013}

показатель только по мировым судьям обоих регионов в совокупности составляет $6 \%$ (5\% в РК и $7 \%$ в ПК), при этом в ПК такой вариант ответа выбрали только мировые судьи. Вероятно, самим носителям судебной власти, непосредственно сталкивавшимся с фактами влияния политической обстановки, «виднее» в выборе ответа на рассматриваемый вопрос. Но можно заключить, что объективно сам институт мировой юстиции, разрешающий малозначительные «бытовые» дела, регулирует судебными средствами такие общественные отношения, которые в преобладающей своей массе далеки от политики, поэтому её влияние на решение мирового судьи минимально.

Интерес представляет распределение ответов на вопрос, касающийся независимости мировых судей. На данный вопрос респонденты могли выбрать несколько вариантов ответов. Большинство из них в качестве фактора, ущемляющего независимость мирового судьи в России, указали назначение мирового судьи на определенный срок (45\%, при этом 44 \% в РК и 47 \% в ПК). На данное обстоятельство ущемления независимости судебной власти чаще указывают мировые судьи, чем гражданские служащие (56 \% против 41 по обоим регионам в совокупности), что объяснимо тем, что данная проблема наиболее волнует самих носителей судебной власти.

Чуть меньше, но почти треть участников опроса (31\%, при этом 26 \% в РК и значительно больше - $44 \%$ - в ПК) считают, что обеспечение деятельности мирового судьи исполнительными органами субъекта Российской Федерации ущемляет независимость судебной власти. Опять же мировых судей данное обстоятельство беспокоит больше - половина служителей фемиды считают таким образом (37\% мировых судей в РК и почти вдвое больше - 67 \% в ПК). В итоге раасматриваемый фактор среди мировых судей в ПК стал преобладающим.

Согласны с тем, что независимость мировых судей ущемляется системой пересмотров решений мирового судьи федеральными судами как вышестоящей инстанцией, 19 \% опрошенных (19\% в РК и 21 \% в ПК), при этом вдвое чаще указанный ответ выбирали гражданские служащие в ПК (26\%), чем мировые судьи того же региона (только $13 \%$ ).

$13 \%$ респондентов (15\% в РК и $9 \%$ в ПК) считают, что независимость мирового судьи ущемляется назначением его законодательными органами субъ- екта Российской Федерации. В ПК такой ответ выбрали исключительно мировые судьи (20\% от всех опрошенных судей ПК).

Наименьшее количество опрошенных указало в качестве фактора, негативно влияющего на судебную независимость, установленный порядок отбора кандидатов на должность мирового судьи (9 \%, при этом $10 \%$ в РК и 6 \% в ПК). Характерно, что данного мнения придерживаются в основном гражданские служащие, многие их которых собирались бы, а может уже участвуют в процедуре прохождения такого отбора. В РК так считает 12 \% гражданских служащих по сравнению с 5 \% мировых судей РК, выбравших такой же вариант ответа, а в ПК на порядок отбора сослались исключительно гражданские служащие (11\%).

$4 \%$ опрошенных дали свой вариант ответа на вопрос о том, что ущемляет независимость мировых судей. Из них 4 респондента (по 1 мировому судье в РК и ПК и 2 гражданских служащих в ПК) считают, что независимость судебной власти ничем не ущемляется, 1 респондент (мировой судья в ПК) считает, что фактором ущемления судебной власти является низкое денежное содержание, не соответствующее статусу мирового судьи.

Таким образом, проведенное нами социологическое исследование позволило выявить некоторые тенденции в представлениях мировых судей и гражданских служащих их аппаратов о проблемах и перспективах развития современного института мировой юстиции в российской политической системе. В целом можно сделать вывод о недооценке политической роли мировой юстиции самими представителями этого института, видение ими перспективы её развития в качестве низшего звена судебной системы. Результаты опроса могут использоваться в политологических и юридических исследованиях, касающихся значения и перспектив развития судебной власти в целом и мировой юстиции как её звена.

\section{Библиография:}

1. Гарифуллина А. Р. Некоторые аспекты организационного обеспечения деятельности мировых судей // Рос. судья. - 2012. - № 6. - С. 5-10.

2. Судебный департамент при Верховном Суде Российской Федерации : [офиц. сайт]. URL: http:// www.cdep.ru/index.php?id=79\&item=1627 (дата обращения: 23.05.2013). 
3. Дорошков В. В. 10-летний юбилей института мировых судей в России и перспективы его дальнейшего развития // Мировой судья. - 2009. - № 1. C. 2-5.

4. Иванова Т. В. Судебная власть в контексте проблемы понимания феномена власти // Вестн. Полоц. гос. ун-та. Cер. D. Эконом. и юрид. науки. 2008. - № 10. - C. 133-138.

5. Муратшина Г. П. Организация судебной власти в Республике Башкортостан (на примере мировых судей) // Мировой судья. - 2012. - № 9. - С. 23-32.

6. Пасечник Н. В. Политические аспекты судебной власти в современной России : Дис. ... канд. полит. наук. - Саратов, 2005. - 189 с.

7. Понасюк А. М. Медиация как альтернатива и дополнение судопроизводству // Мировой судья. 2012. - № 9. - С. 8-9.

8. Ржевский В. А., Чепурнова Н. М. Судебная власть в Российской Федерации: конституционные основы организации и деятельности. - М.: Юрист, 1998. - 235 c.

9. Салчак А. А. Мировая юстиция в Республике Тыва (проблемы законодательного регулирования деятельности мировых судей) // Мировой судья. - 2010. - № 12. - С. 2-6.

10. Серый В. В. Имидж судебной власти в России как отражение социально-политических процессов : Автореф. дис. ... канд. полит. наук. - М., 2011. -25 c.

11. Терехин В. А. К вопросу о возможности передачи мировой юстиции на федеральный уровень // Рос. юстиция. - 2009. - № 2. - С. 27-31.

\section{References (transliteration):}

1. Garifullina A. R. Nekotorye aspekty organizacionnogo obespecheniya deyatel'nosti mirovyh sudey // Ros. sud'ya. - 2012. - № 6. - S. 5-10.

2. Doroshkov V. V. 10-letniy yubiley instituta mirovyh sudey v Rossii i perspektivy ego dal'neyshego razvitiya // Mirovoy sud'ya. - 2009. - № 1. - S. 2-5.

3. Ivanova T. V. Sudebnaya vlast' v kontekste problemy ponimaniya fenomena vlasti // Vestn. Poloc. gos. un-ta. Ser. D. Ekonom. i yurid. nauki. - 2008. - № 10. - S. 133-138.

4. Muratshina G. P. Organizaciya sudebnoy vlasti v Respublike Bashkortostan (na primere mirovyh sudey) // Mirovoy sud'ya. - 2012. - № 9. - S. 23-32.

5. Pasechnik N. V. Politicheskie aspekty sudebnoy vlasti v sovremennoy Rossii : Dis. ... kand. polit. nauk. Saratov, 2005. - 189 s.

6. Ponasyuk A. M. Mediaciya kak al'ternativa i dopolnenie sudoproizvodstvu // Mirovoy sud'ya. - 2012. - № 9. - S. 8-9.

7. Rzhevskiy V. A., Chepurnova N. M. Sudebnaya vlast' v Rossiyskoy Federacii: konstitucionnye osnovy organizacii i deyatel'nosti. - M.: Yurist, 1998. - 235 s.

8. Salchak A. A. Mirovaya yusticiya v Respublike Tyva (problemy zakonodatel'nogo regulirovaniya deyatel'nosti mirovyh sudey) // Mirovoy sud'ya. 2010. - № 12. - S. 2-6.

9. Seryy V. V. Imidzh sudebnoy vlasti v Rossii kak otrazhenie social'no-politicheskih processov : Avtoref. dis. ... kand. polit. nauk. - M., 2011. - $25 \mathrm{~s}$.

10. Terehin V. A. K voprosu o vozmozhnosti peredachi mirovoy yusticii na federal'nyy uroven' // Ros. yusticiya. - 2009. - № 2. - S. 27-31. 